\title{
ИННОВАЦИОННЫЕ ДЕТЕРМИНАНТЫ ЭФФЕКТИВНОЙ ИНТЕГРАЦИИ БЕЛОРУССКОЙ ЭКОНОМИКИ В МИРОВУЮ ХОЗЯЙСТВЕННУЮ СИСТЕМУ В УСЛОВИЯХ ГЛОБАЛИЗАЦИИ
}

\begin{abstract}
В статье рассматривается механизм становления в мировой экономике инновационной парадигмы развития. Анализируются возможности эффективной интеграции Беларуси в мировое экономическое пространство, исходя из уровня развития национального научно-технического потенциала

К концу XX столетия в мировой экономике сформировались три базовые тенденции, которые в основном и будут определять ее развитие в ближайшие десятил етия. Первая - это процесс глобализации, направленный на создание единого мирового хозяйства, вторая - наступление нового этапа научнотехнического развития, связанного с началом формирования VI технологического уклада. К третьей важнейшей мировой тенденции. можно отнести процесс транснационального корпорирования ( рисунок 1 ).
\end{abstract}

\footnotetext{
1 Андрей Викторович Марков, доктор экономических наук, профессор, первый проректор Института парламентаризма и предпринимательства, лауреат премии Национальной академии наук Беларуси.
} 


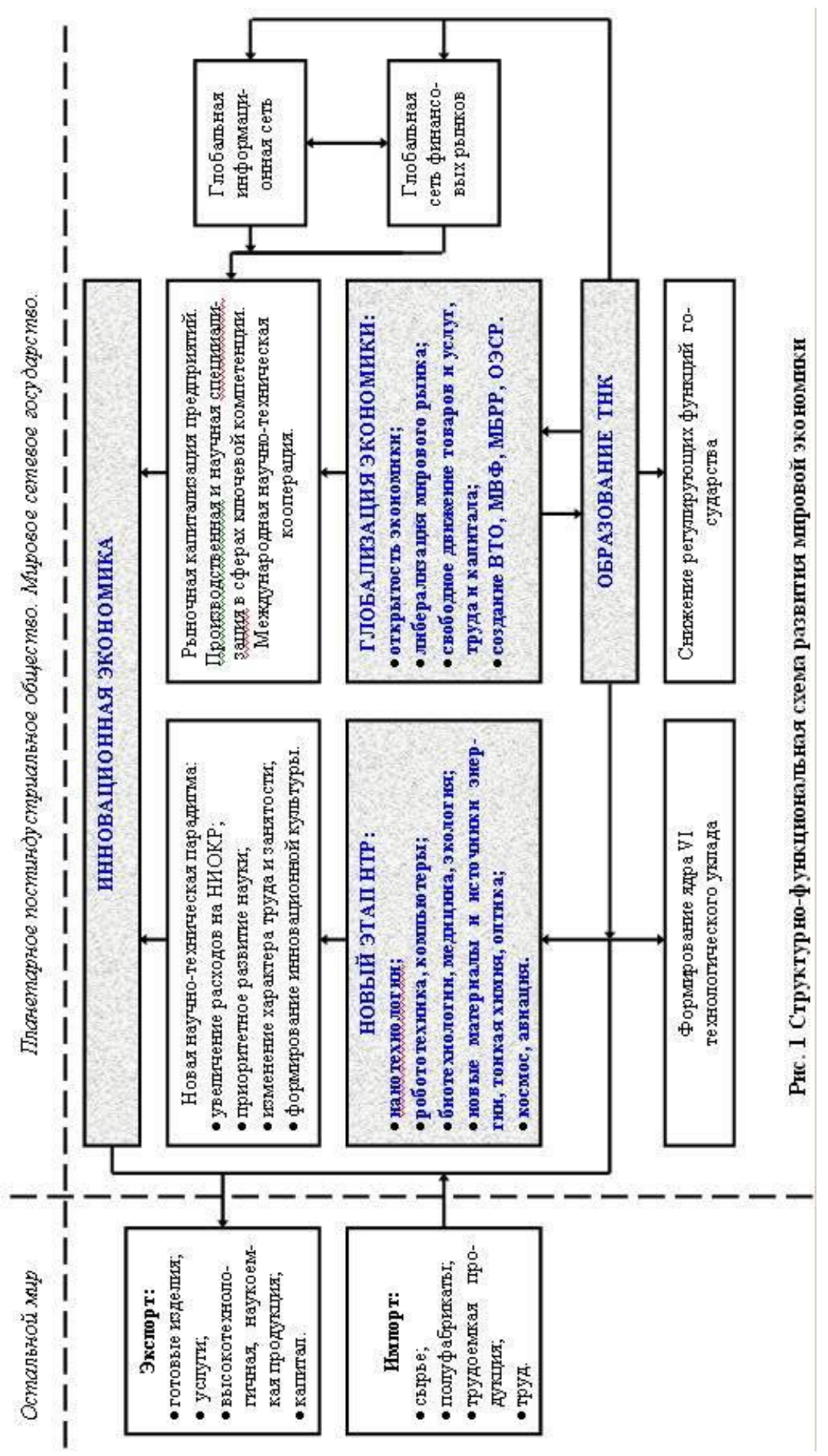


Несмотря на их общую взаимную обусловленность, две первые составляющие интегрального цивилизационного вектора развития инициируются и являются результатом деятельности крупных межгосударственных экономических образований, таких как транснациональные корпорации (ТНК) и международные финансово-промышленные группы. Сегодня объем деятельности последних превышает 50 \% мирового производства и составляет около $2 / 3$ оборота мировой торговли, которая в современных условиях служит скорее показателем интернационализации производства, чем характеристикой экспортного потенциала национальной экономики. Согласно статистике ООН ТНК являются собственниками $30 \%$ мирового частного сектора, контролируют более $90 \%$ патентов и лицензий, производят основную массу высокотехнологичной продукции $[1$, c. 64$]$.

Основанный на эффективном использовании сравнительных преимуществ отдельных стран этот процесс начался еще в 70-х годах прошлого века и особенно усилился в его последнем десятилетии после либерализации финансовой деятельности международных банков. К концу 90-х годов деятельность ТНК в силу своего интернационального характера начинает разрывать национальные границы государств, требуя открытости их экономик, свободного перемещения труда и капитала. Они создают либеральную мировую рыночную систему и используют для ее регулирования наднациональные органы, такие как Всемирная торговая организация, Международный валютный фонд, Международный банк реконструкции и развития, Организация экономического сотрудничества и развития и др.

Весьма обоснованным в этом контексте можно считать мнение о том, что преимущества глобализации мирового развития в наибольшей мере доступны наиболее развитым индустриальным странам, в силу чего разрыв, существующий между ними и государствами, находящимися на более низком уровне научнотехнического развития, лишь усиливается. Но с другой стороны, после распада СССР в мире не осталось государств с самодостаточной экономикой, которые могли бы себе позволить игнорировать этот объективный процесс, поэтому его следует рассматривать как историческую данность. Вопрос состоит лишь в том, готовы ли развивающиеся страны наряду с переходом к рыночным отношениям формировать у себя такую хозяйственную систему, которая позволила бы им достойно встроиться в новую схему мировых экономических отношений.

Согласно определению экспертов ОЭСР глобализация мировой экономики характеризуется следующими основными признаками [ 2, с. 211 ]:

- границы между различными каналами и формами международных связей стираются, происходит их взаимопроникновение;

- сотрудничество между фирмами охватывает технологии, ресурсы и производство продукции вне национальных границ;

- $\quad$ зарубежные инвестиции ведут к распределению активов и собственности фирм между различными странами;

- расширяется торговля в рамках транснациональных компаний, между их подразделениями, расположенными в разных странах, что, таким образом, меняет характер интеграции отраслей на международном уровне; 
- связи между мировыми финансовыми центрами позволяют обеспечить международное движение частных сбережений и межстрановое взаимодействие кредиторов и заемщиков;

- технической основой формируемых глобальных связей служат компьютерные и телекоммуникационные сети. Именно эти радикальные инновации придали глобальной экономике новое качество, резко повысив производительность труда и изменив его характер.

Ее сердцевину составляет глобальная сеть финансовых рынков, на которых инвесторы, используя компьютерные модели, анализируют информацию в режиме реального времени и имеют возможность переводить свои капиталы в любую точку мира одновременно с принятием решения об их трансфере. Сами финансовые рынки характеризуются при этом системной волатильностью, когда цены на них постоянно колеблются вокруг отдельных трендов. Традиционные регулятивные меры, имеющиеся в распоряжении национальных правительств, становятся все более ограниченными так как, с одной стороны, финансовая волатильность имманентна глобальной экономике, с другой - в условиях расширения и углубления процесса глобализации принятие решений национальными правительствами в значительной степени происходит уже в "мировом сетевом государстве" [3, с. 177, $178]$.

Основным критерием деятельности предприятия в мировом сетевом государстве становится его котировка на финансовых рынках, которая определяется всё более сложным образом в результате обработки постоянно возрастающих объемов и источников информации. На стоимость объекта инвестиций помимо традиционных экономических показателей всё большее влияние оказывают "информационные турбулентности", имеющие разнообразное происхождение. Предприятие, желающее повысить свою рыночную стоимость, должно формировать в системе глобальных сетей свой виртуальный имидж, который зависит от умения предложить потенциальному партнеру "будущее", которое благодаря нему наступит быстрее, чем благодаря его конкурентам. Такие компании во многом отказываются от банковского регулирования движения капитала и получают требуемые инвестиции на глобальном фондовом рынке. При этом увеличение иностранного участия в их бизнесе только стимулирует их инновационную деятельность [3, с. 28 , 40, 41].

Следует отметить, что новая экономическая система включает в свою сеть те страны, которые, с одной стороны, имеют для этого соответствующие технологические возможности, а с другой - представляют для нее практический интерес, придавая им тем самым дополнительную ценность и еще более увеличивая разрыв в научно-техническом развитии с менее развитыми государствами. Таким образом, успех страны в этих условиях зависит от ее способности стать, своего рода, "узлом" в глобальных сетях мирового капитала.

Характерной чертой современной экономики является также то, что объем международной торговли растет в два раза быстрее, чем мировые объемы производства, а иностранные инвестиции - в три раза быстрее, чем торговля. Изменилась и товарная структура мирового экспорта. За последние полвека втрое снизилась доля продукции сельского хозяйства и добывающей промышленности. При этом вдвое выросла доля продуктов нефтехимии, технологического 
оборудования, втрое - автотранспорта, в 12 раз доля телекоммуникационного оборудования. Преобладающее место в мировом товарном экспорте сегодня занимают готовые изделия, 80 \% которых поставляют на мировые рынки промышленно развитые страны. При этом, доля высокотехнологичной продукции в структуре их товарного экспорта за последние 20 лет увеличилась в среднем в два раза. Объемы производства в высокотехнологичном секторе экономики растут в 2,5 раза более быстрыми темпами, чем в других отраслях обрабатывающей промышленности [1, с. 69].

Кроме того, индустриально развитые страны являются не только основными производителями, но и потребителями высокотехнологичной продукции, 80 \% и более которой оседает на их внутренних рынках Аналогичным образом выглядит и глобальная инвестиционная политика, когда 90 \% прироста прямых иностранных инвестиций приходится на основную группу экспортирующих их государств Они устанавливают на глобальных рынках "правила игры" по обмену товарами и услугами, завышая цену на продукцию собственного производства и занижая ее на продукцию, производимую развивающимися или приравненными к ним странами. Причина такой узаконенной дискриминации в одном - их продукция более высокотехнологична и наукоемка. Цена на нее определяется не столько издержками производства, сколько уровнем заложенных в ней ноу-хау, создающими ей высочайший уровень конкурентоспособности. [1, с. 76].

Разработка высоких технологий, производство на их основе высокотехнологичной продукции (товаров и услуг), выход с ней на мировые рынки, расширение международной интеграции в этой области стали для развитых стран важнейшей стратегией экономического роста. Как показали исследования, проводившиеся в странах ОЭСР, лишь в незначительной степени их долгосрочный экономический рост определяется физическим приращением в производство труда и капитала; результирующую роль в нем играет повышение общей производительности факторов производства, детерминируемое прежде всего научно-техническим прогрессом.

Создание высококонкурентной продукции основывается на использовании самых современных технологий, относящихся к области:

- наноматериалов;

- информатики и телекоммуникаций;

- микробиологии, генетики и биохимии;

- тонкой химии;

- $\quad$ разработки новых материалов и новых источников энергии;

- $\quad$ авиакосмической и лазерной техники, оптики;

- медицины и экологии.

Именно эти технологии составляют ядро находящегося в фазе роста VI технологического уклада, который внедряется в промышленно развитых странах в существующие социально-экономические отношения и формирует под них новую инновационную парадигму развития. К ее основным положениям можно отнести:

- $\quad$ резкий рост издержек на инновационную деятельность, позволяющий быстро осваивать базовые нововведения и создавать на их основе новые производства; 
- $\quad$ глобальные изменения характера труда, связанные с возрастанием объемов его интеллектуальной составляющей и расширением сферы услуг, также качественно изменяющейся за счет увеличения доли информационного сервиса;

- приоритетное развитие науки, являющейся определяющим фактором научнотехнического прогресса, которое составляет основу роста национального благосостояния и повышения конкурентоспособности экономики.

Переходя к конкурентоспособности, отметим, что, по определению, принятому в ОЭСР, она формулируется как способность компаний, отраслей, регионов и наций обеспечивать постоянно высокий уровень доходов и заработной платы населения, оставаясь при этом открытыми для международной конкуренции. В нем отражается новый, инновационный этап эволюции источников национальной конкурентоспособности. Если традиционно на передний план выдвигались: выгодное географическое положение, обладание богатыми и доступными природными ресурсами, благоприятные климатические условия и низкие ценовые факторы производства (прежде всего труда), то в настоящее время акценты смещаются в сторону уровня развития научно-технического потенциала и образования,

К числу интегральных показателей межстрановой конкурентоспособности относится "полная факторная производительность", измеряющаяся количеством продукции, произведенной на единицу совокупных затрат труда и капитала. Согласно такому подходу, отражающему реальное сближение понятий производительности и конкурентоспособности, страна, имеющая технологические преимущества, может быть конкурентоспособной на мировых рынках, поддерживая при этом высокие доходы и уровень жизни населения. Это конкурентоспособность богатых стран, основанная на выгодах использования современных высоких технологий. Однако конкурентоспособность страны иногда может быть достигнута и на базе нетехнологических преимуществ - прежде всего благодаря низкой стоимости факторов производства или девальвации национальной валюты, то есть за счет снижения уровня жизни населения. Это конкурентоспособность бедных стран, которая в силу своей специфики носит недолговечный преходящий характер.

Таким образом становится очевидным, что от способности страны к скорейшей адаптации результатов научно-технического прогресса, их имплантации в реальную экономику, напрямую зависит возможность ее эффективного развития. Тогда, отталкиваясь от идеологии процессов, отображенных на представленной выше структурно-функциональной схеме, можно констатировать становление в мировой экономике инновационной парадигмы развития.

Каковы в данном контексте возможности Беларуси по дальнейшему расширению и диверсификации ее внешнеэкономической деятельности? Произведем эту оценку на основе анализа статистических данных, наиболее полно характеризующих ее инновационный потенциал с позиции стратегической перспективы.

В настоящее время в Беларуси научные исследования и разработки выполняют более 500 организаций, включая субъекты малого научно-инновационного предпринимательства. Технологическую проблематику страны обслуживает Национальная академия наук, отраслевые НИИ и учреждения высшего образования. 
Однако их вклад в модернизацию народного хозяйства мог быть намного значительнее если бы не низкий уровень финансирования. Так наукоемкость национального ВВП в последние два десятилетия не превышала 1\% (0,7\% в 2010 г.), что значительно уступает странам-мировым лидерам в рейтинге по индексу технологического развития (Швеция, Финляндия - до 4\%, США и страны ЕС - до $3 \%$ ). Аналогичное положение складывается и с затратами на технологические инновации, размер которых в процентах к ВВП ( $2 \%$ в 2010 г.) в Беларуси вчетверо ниже, чем в развитых странах мира. [4, с. 26-190].

В результате возможности Беларуси в области инновационного развития априори будут ниже, чем у ее потенциальных конкурентов как в абсолютном, так и в относительном выражении (рисунки 2-4).

Рис. 2

Таблщца 2

Теор етические сценарии экономпческого роста.

\begin{tabular}{|c|c|c|c|c|c|c|c|c|c|}
\hline $\begin{array}{c}\text { Сце } \\
\text { нари } \\
\text { й }\end{array}$ & BB & IIII & BBII & $\begin{array}{l}\text { Даля ВВПI } \\
\text { в BB }\end{array}$ & $\begin{array}{l}\text { Рать НTII } \\
\text { в росте } \\
\text { ВBII, } \%\end{array}$ & $\begin{array}{c}\text { Характер } \\
\text { экономпческого } \\
\text { роста }\end{array}$ & Факторы влияния & $\begin{array}{l}\text { Эоономический } \\
\text { эффктт }\end{array}$ & Социатьньй эффект \\
\hline 1. & $>$ & $<$ & $>$ & $>$ & 100 & 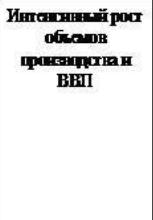 & 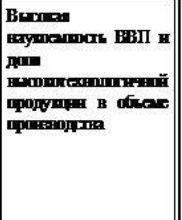 & 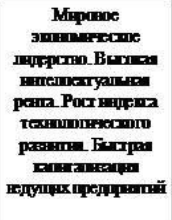 & 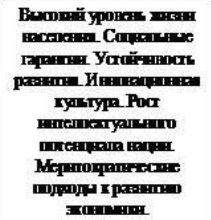 \\
\hline 2 & const & $<$ & $>$ & $>$ & 100 & 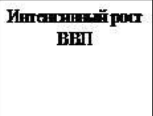 & 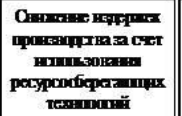 & 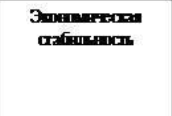 & 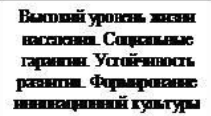 \\
\hline 3. & $>$ & $>$ & $>$ & most & - & 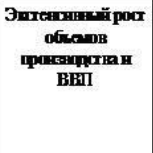 & 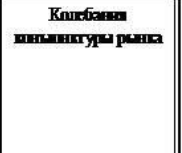 & 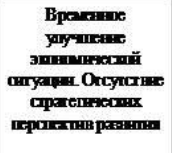 & 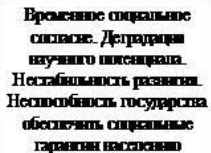 \\
\hline
\end{tabular}

Обознатения: ВB - валовьй вьпуск; IIII - промежуточное потреб̆ленне; ВВП - валовьй внутреннй пр одукт; НТI - научно-техннческий пр огресс; >- рост; <- сннженне; const - неизменность. 


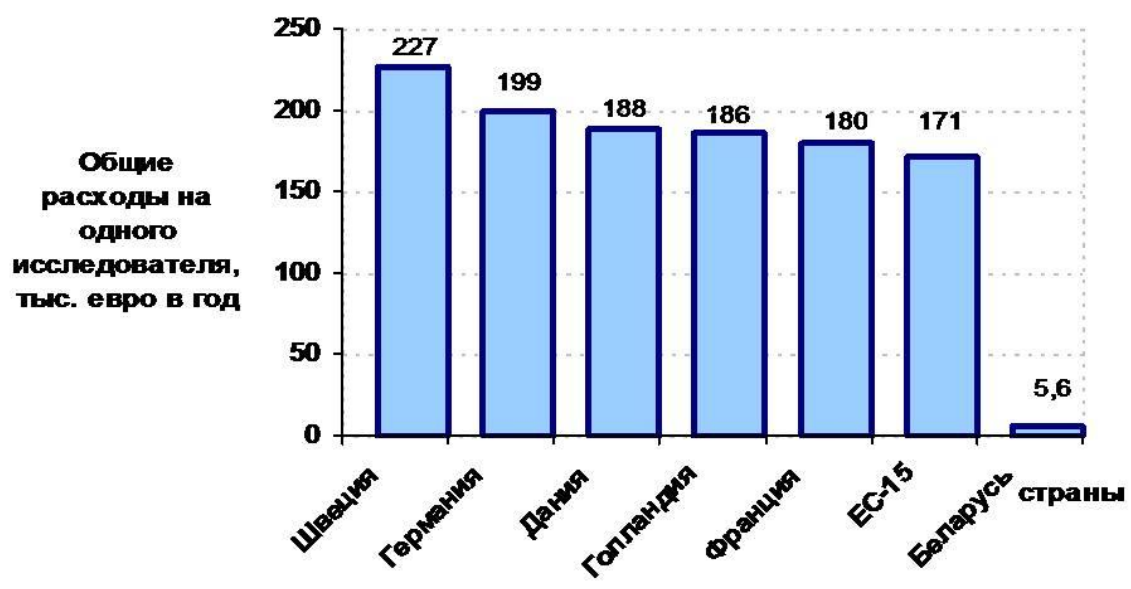

Рис.3 Сопоставимые расходы на одного исследователя. 


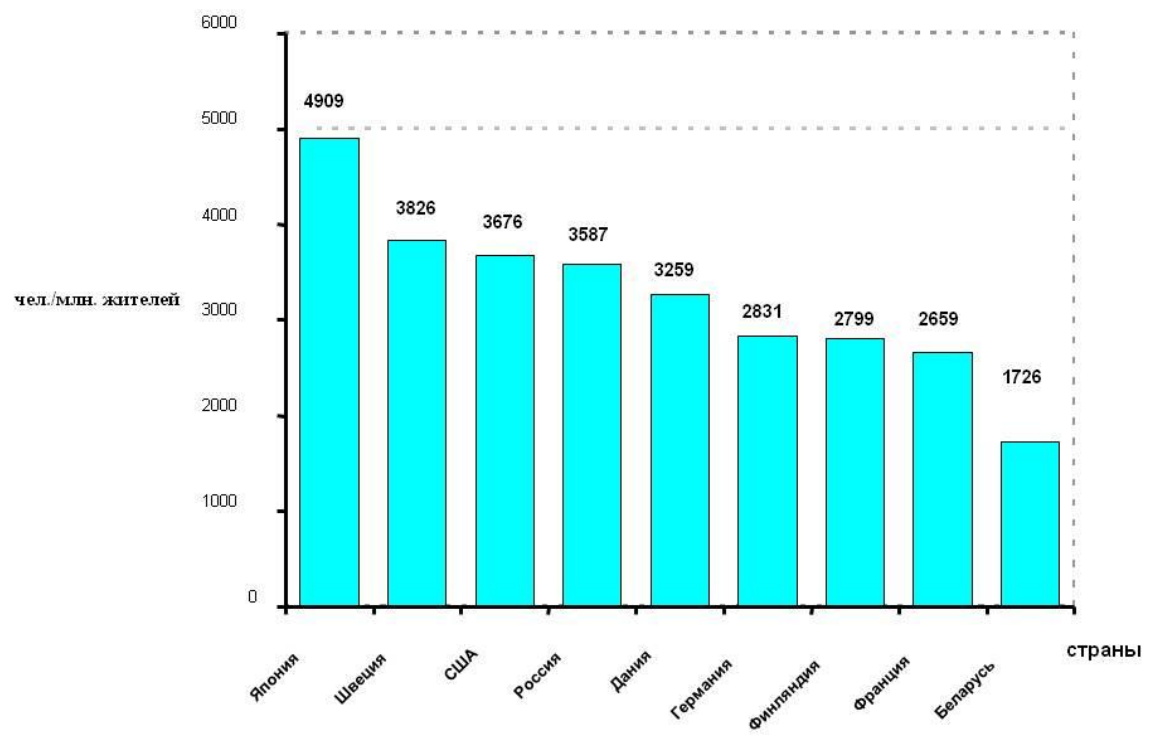

Рис 4. Количество исследователей на 1 млн. жителей.

К этому можно добавить наличие в белорусской экономике таких отрицательных факторов влияния как неразвитость рынка научно-технической продукции и его инфраструктуры, низкий стимуляционный уровень регулятивных воздействий государства на процессы инновационной трансформации производства.

Следствием неадекватности сложившегося в стране инновационного климата тем требованиям, которые предъявляются к современной экономике постиндустриальным обществом, является ее низкая укладность (порядка 25\% продукции, производимой в Беларуси, относится к I - III технологическим укладам, $70 \%$ - к IV и только около 5\% - к V ), невыраженный высокотехнологичный экспорт, незначительная инновационная активность промышленных предприятий, неразвитость малого научно- инновационного бизнеса ( рисунки 5-7 ). 


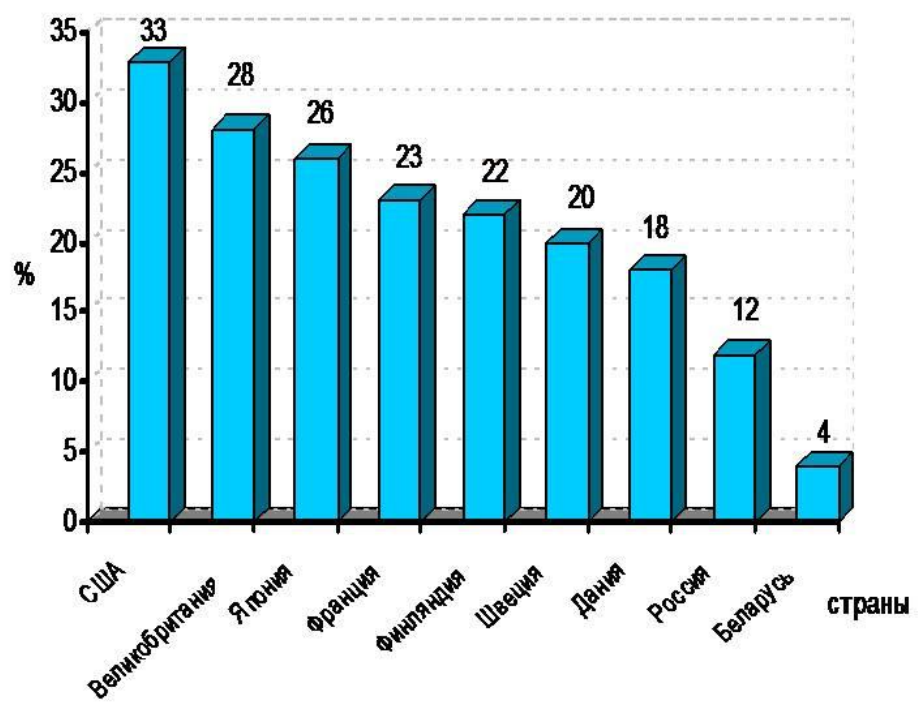

Рис.5 Высокотехнологичный экспорт в \% к объему экспорта. 


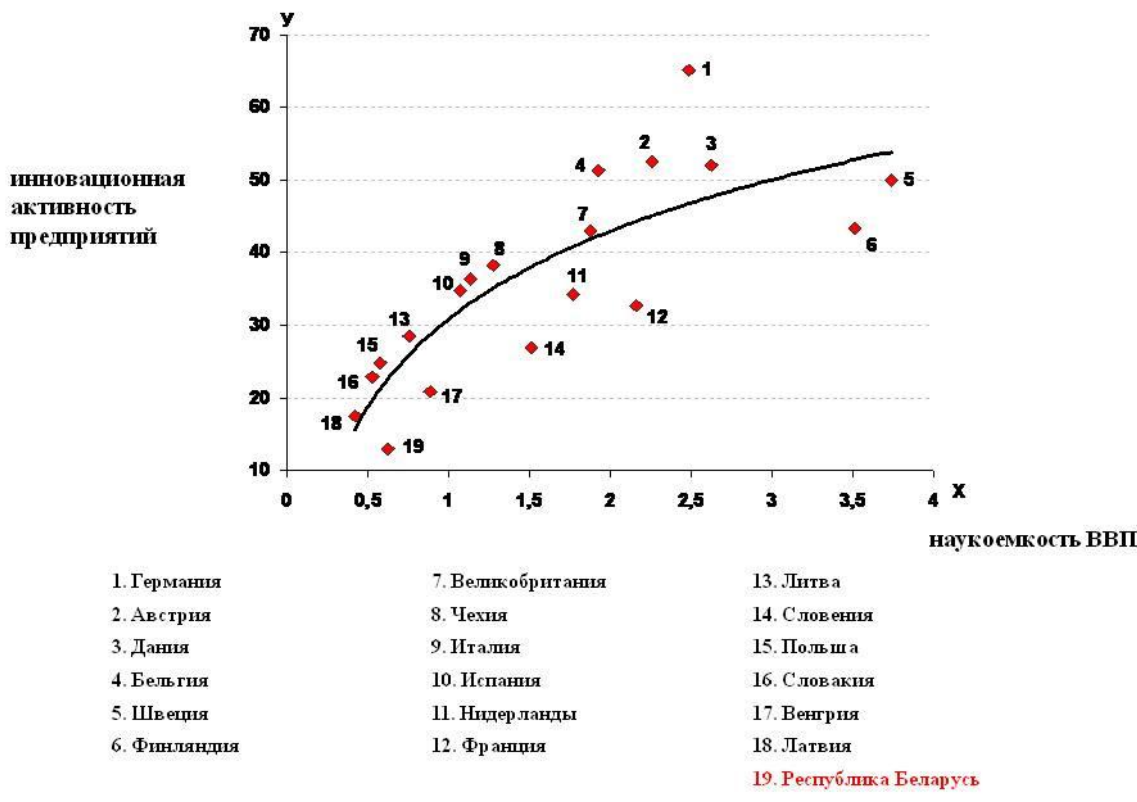

Рис. 6 Эмпирическая зависимость инновационной активности промышленных предприятий от наукоемкости ВВП

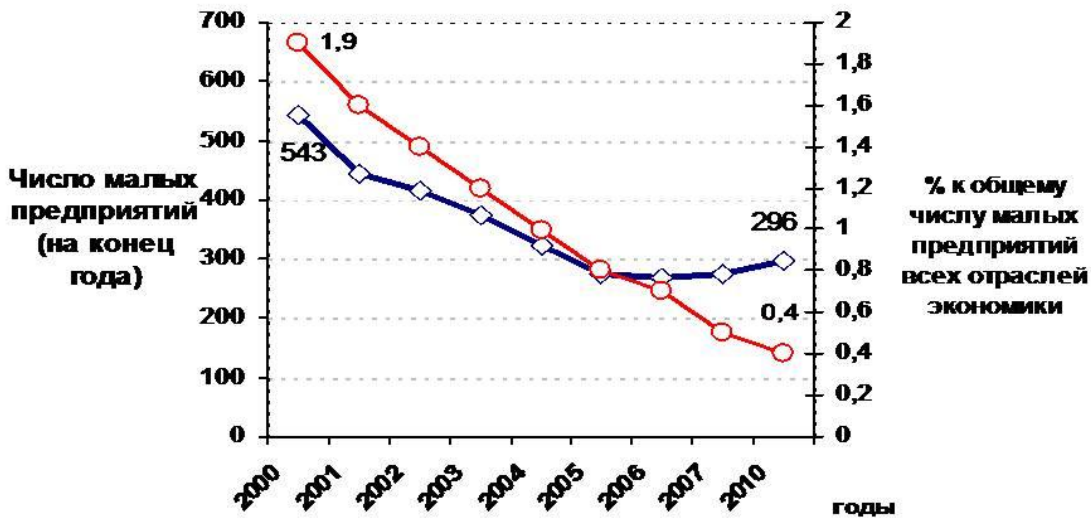

Рис. 7 Динампка чшсленности мальх научно-инноващинных предприятий в Беларуси и их доля в сфере малого бизнеса 
Но, пожалуй, самым негативным в сложившемся положении является то, что при экспортоориентированной структуре экономики (отношение внешнеторгового оборота к ВВП в Беларуси вдвое выше чем в высокоразвитой Германии ) все последние годы происходил опережающий рост внутреннего потребления по отношению к росту экспорта (таблица 1).

Таблица 1. Сравнительная динамика роста импорта промежуточных товаров

\begin{tabular}{|l|c|c|c|c|c|}
\hline \multicolumn{1}{|c|}{ Годы } & 2005 & 2006 & 2007 & 2008 & 2009 \\
\hline $\begin{array}{l}\text { Отношение импорта } \\
\text { промежуточных } \\
\text { товаров к экспорту } \\
\text { товаров, \% }\end{array}$ & $\mathbf{7 4 , 6}$ & 79,8 & $\mathbf{8 5 , 2}$ & $\mathbf{8 8 , 1}$ & $\mathbf{9 7 , 3}$ \\
\hline
\end{tabular}

Это обусловлено тем, что невысокая доля добавленной стоимости в цене экспортируемой продукции не обеспечивала компенсацию растущих затрат на промежуточный, главным образом сырьевой, импорт. А это, в свою очередь, является следствием высокой затратности отечественного производства. Достаточно сказать, что энергоёмкость ВВП страны, как минимум, вдвое превышает аналогичный показатель развитых стран[6, с. 217].

Очевидно, что наличие в экономике страны интенсивных факторов производства дает ей возможность развиваться по одному из предпочтительных (№1, 2) сценариев экономического роста (таблица 2). Однако в Беларуси в структуре последнего по прежнему превалирует экстенсивная составляющая (сценарий №3), что графически подтверждается эквидистантностью кривых, представленных на рисунке 8 .

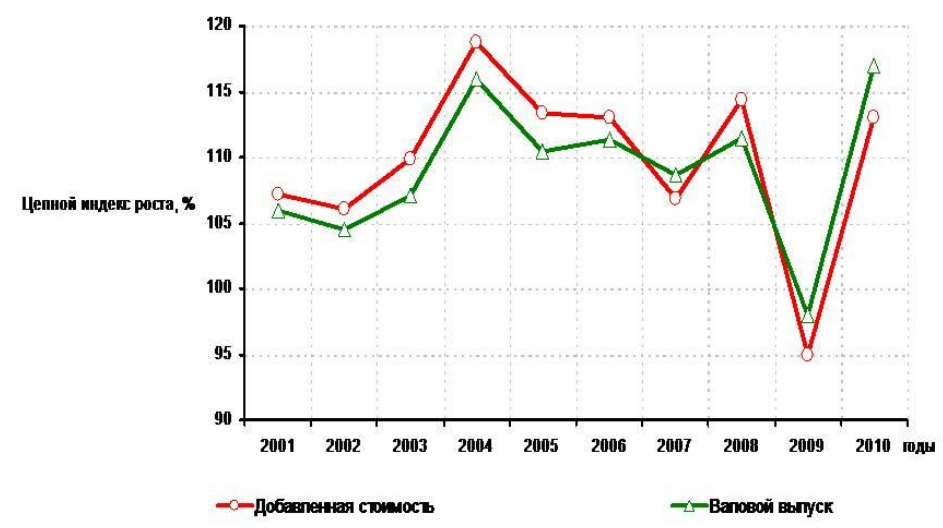

Рис. 8 Динампка объемов валовоговьпускаи валовоговнутр еннего продукта в пр омьшленности Беларуси в цепньх индексах роста. 
В итоге можно сделать только один вывод - необходимо менять инвестиционные приоритеты страны, ориентируя их по инновационному вектору! Здесь важно понимать, что сегодня в глобальной экономике идет активное становление VI технологического уклада, провоцирующего мегаэкономические финансовые турбулентности и системные кризисы И в этих условиях ведущие мировые державы вкладывают огромные средства в развитие нанотехнологий, (рисунок 9). которые уже завтра станут ядром новой экономики .[7, с. 4-6].

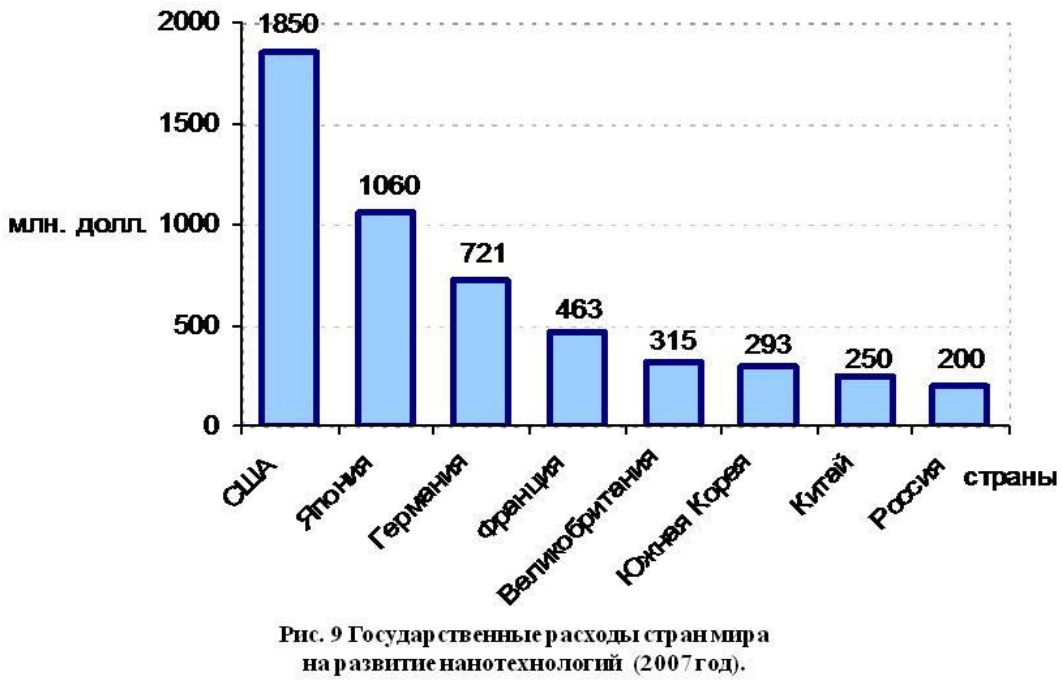

Тогда страна, которая хочет в будущем проводить самостоятельную государственную инновационную политику, а не находиться в роли перманентного акцептора, должна приложить максимум усилий для того, чтобы пусть и на кооперационных началах, но принять участие в набирающей силу гонке за мировым технологическим лидерством.

\section{ЛИТЕРАТУРА:}

[1] Марков А.В., Государственная инновационная политика: теоретические основы и механизм реализации, Мн.: Право и экономика, 2005. - 370 с.

[2] Technology and the Economy: The Key Relationships, Paris: OECD, 1992

[3] Кастельс М., Химанен П. Информационное общество и государство благоденствия: Финская модель, М.: Логос, 2002. - 219 с.

[4] Наука, инновации и технологии в Республике Беларусь 2010: Стат. сб. - Мн.: ГУ „БелИСА” 2010. - 196 с.

[5] Национальная программа развития экспорта Республики Беларусь на 2011-2015 годы. Министерство иностранных дел Республики Беларусь, Национальная академия наук Беларуси, Институт экономики, Мн., 1999. -145 с. 
[6] Марков А. В., Эндогенные факторы белорусского финансово-экономического кризиса.Регіональна економіка, 2012, №1.-С.214-223

[7] Глазьев С.Ю., Кризисы, антикризисные меры и стратегия инновационного народнохозяйственного развития в зеркале теории долгосрочной мегатехнологической динамики, Российский экономический журнал, 2008 - №12.-С.3-9.

\section{INNOVATIVE MECHANISMS OF EFFICIENT INTEGRATION OF BELARUS ECONOMY IN THE WORLDWIDE ECONOMIC SYSTEM OF THE GLOBALISATION CONDITIONS}

The article discusses the mechanisms of formation of the global economy of innovative development paradigm. The possibilities of an efficient integration of Belarus into the world economy, based on the level of development of national scientific and technological capacity were discussed.

DOI: 10.7862/rz.2012.zim.2 